\title{
Modeling the Dynamic Linkage between Renewable Energy Consumption, Globalization, and Environmental Degradation in South Korea: Does Technological Innovation Matter?
}

\author{
Tomiwa Sunday Adebayo 1(D, Manuel Francisco Coelho ${ }^{2,3, *}$, Dilber Çağlar Onbaşığlu ${ }^{4}$, Husam Rjoub ${ }^{5, *}$,

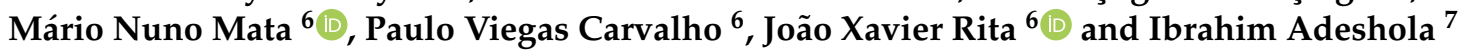

Citation: Adebayo, T.S.; Coelho, M.F.; Onbaşıŏlu, D.Ç.; Rjoub, H.; Mata, M.N.; Carvalho, P.V.; Rita, J.X.; Adeshola, I. Modeling the Dynamic Linkage between Renewable Energy Consumption, Globalization, and Environmental Degradation in South Korea: Does Technological Innovation Matter? Energies 2021, 14, 4265. https://doi.org/10.3390/en14144265

Academic Editors: Ricardo J. Bessa and Yuriy Bilan

Received: 7 June 2021

Accepted: 10 July 2021

Published: 14 July 2021

Publisher's Note: MDPI stays neutral with regard to jurisdictional claims in published maps and institutional affiliations.

Copyright: (c) 2021 by the authors. Licensee MDPI, Basel, Switzerland. This article is an open access article distributed under the terms and conditions of the Creative Commons Attribution (CC BY) license (https:/ creativecommons.org/licenses/by/ $4.0 /)$
1 Department of Business Administration, Faculty of Economics and Administrative Science, Cyprus International University, Northern Cyprus, Mersin 10 99040, Turkey; twaikline@gmail.com

2 Instituto Superior de Economia e Gestão/Universidade de Lisboa, Rua Miguel Lupi 20, 1249-078 Lisboa, Portugal

3 SOCIUS/ISEG Centro de Investigação em Sociologia Económica e das Organizações, 1249-078 Lisboa, Portugal

4 Department of Accounting, Karmi Campus, Girne American University, University Drive, P.O. Box 5, Karaoglanoglu, TRNC, Kyrenia 99428, Turkey; caglardilber@hotmail.com

5 Department of Accounting and Finance, Faculty of Economics and Administrative Sciences, Cyprus International University, North Cyprus, Mersin 10 99040, Turkey

6 ISCAL-Instituto Superior de Contabilidade e Administração de Lisboa, Instituto Politécnico de Lisboa, Avenida Miguel Bombarda 20, 1069-035 Lisboa, Portugal; mnmata@iscal.ipl.pt (M.N.M.); jpcarvalho@iscal.ipl.pt (P.V.C.); jmrita@iscal.ipl.pt (J.X.R.)

7 Department of Information Technology, School of Computing and Technology, Eastern Mediterranean University, North Cyprus, Mersin 10 99040, Turkey; Ibrahim.adeshola@emu.edu.tr

* Correspondence: coelho@iseg.ulisboa.pt (M.F.C.); hrjoub@ciu.edu.tr (H.R.)

Abstract: The present research assesses the influence of globalization and technological innovation on $\mathrm{CO}_{2}$ emissions in South Korea as well as taking into account the role of renewable energy consumption and energy consumption utilizing datasets between 1980 and 2018. The autoregressive distributed lag (ARDL) bounds testing method is utilized to assess long-run cointegration. The outcome of the ARDL bounds test confirmed cointegration among the series. Furthermore, the ARDL reveals that economic growth, energy consumption and globalization trigger environmental degradation while technological innovation improves the quality of the environment. In addition, the study employed the frequency domain causality test to capture causal linkage among the series. The major advantage of this approach is that causal linkage between series can be captured at the short, medium and long term, respectively. The outcomes of the causality test revealed that globalization, technological innovation, economic growth and energy use can predict $\mathrm{CO}_{2}$ emissions in South Korea.

Keywords: $\mathrm{CO}_{2}$ emissions; globalization; technological innovation; renewable energy consumption; South Korea

\section{Introduction}

Climate change is the most pressing challenge of the 21st century, and greenhouse gas (GHGs) emissions are the primary cause. According to British Petroleum (BP), total global $\mathrm{CO}_{2}$ emissions from fossil energy were 33,890.8 million tons in 2018, up from 11,190 million tons in 1965 . $\mathrm{CO}_{2}$ emissions from utilization of energy increased by $0.5 \%$, less than half the 10 -year average annual growth rate of $1.1 \%$. Nonetheless, this only partly reversed some of the year's abnormally high growth $(2.1 \%)$. Extreme weather events contributed to the significant upsurge in $\mathrm{CO}_{2}$ emissions in 2018 [1]. Global warming has never before posed such a significant threat to human lives and activity. The presence of air contamination and severe weather conditions, as is regularly witnessed, pose substantial health risks 
to humans [2]. In this respect, it is critical to pay significant awareness to the topic of climate change; else, the dangers and concerns associated with climate change, which are predicted to rise in the future years, will have disastrous consequences for safety and human health $[3,4]$.

Technological innovation (TI) performs an important role in reducing emissions while also assisting in energy saving. Furthermore, TI performs a vital role in the effective utilization of both traditional and renewable energy (RE) sources. Furthermore, TI can assist in the development of new RE sources. Technological advancements also enhance RE capability, hence improving the potential RE supply to satisfy the demand of energy in the future. Due to the ever-increasing need for energy, it is established that RE will be the most significant form of energy in the future, and it is also an environmentally benign source of power. We discovered a wealth of information on the influence of renewable energy on environmental pollution. To address $\mathrm{CO}_{2}$ emissions, the majority of prior research recommends increasing the amount of renewable energy in the total energy mix.

The importance of TI in reducing $\mathrm{CO}_{2}$ emissions is clearly established in the recent literature, although it is not given adequate attention. There are a few studies that have looked at the direct influence of TI on $\mathrm{CO}_{2}$ emissions, but the results are varied. For example, studies of Ahmad et al. [5], Jin et al. [6], Ahmed et al. [7] and Adebayo and Kirikkaleli [7] found negative technological innovation and $\mathrm{CO}_{2}$ emissions association while the studies of Su and Moaniba [8], Dinda [9] and Shahbaz et al. [10] established positive technological innovation and $\mathrm{CO}_{2}$ emissions association. However, the studies of Ali et al. [11], Shaari et al. [12] and Garrone and Grilli [13] found an insignificant connection between technological innovation and $\mathrm{CO}_{2}$ emissions. Even though the available research showed inconsistent proof of TI role in $\mathrm{CO}_{2}$, its significance for $\mathrm{CO}_{2}$ cannot be overlooked. We cannot rule out the potential that TI performs a key role in the global spread of renewable energy sources.

In recent years, scholars have focused disproportionately on the connections between energy resources, globalization, and their usage. The theoretical foundation for this connection is simple: as nations grow more globalized, their need for energy rises as well. It is a widely held belief that as globalization progresses, trade barriers fall, resulting in an increase in a country's output and revenue. A rise in energy consumption is linked with increases in income and production. As it is often assumed that growing globalization is related with greater levels of economic growth, it is commonly assumed that globalization is a source of rising energy consumption. Nevertheless, the extant research contains contradictory conclusions on this subject. For example, the studies of Shahbaz et al. [10], Kalayci [14] and Rahman [15] found positive association between globalization and $\mathrm{CO}_{2}$ emissions. Globalization's gain in wealth and productivity is eventually augmented by technology spillovers in exporting countries; therefore it is likely that over a given length of time, globalization will reduce consumption of energy and $\mathrm{CO}_{2}$ emissions. We can look at the service sectors of contemporary economies such as the United States and the European Union, where employment is being relocated to emerging economies, and given that consumption of energy in these sectors is less than in industrial production.

Globalization has a favorable ecological impact on exporting nations in this way. Numerous research studies have identified a negative association between globalization and ecological deterioration. For instance, Shahbaz et al. [16], Haseeb et al. [17] and Zaidi et al. [18] established a negative globalization and $\mathrm{CO}_{2}$ emissions association. The ecological effects of globalization differ from nation to nation and area to area, according to these considerations. Globalization does not have the same impact on all nations. In the process of globalization, several leaders and laggards can be discovered. As a result, the globe map depicts the nations that are most and least globalized. We may apply the same logic to globalization and energy linkages; however, the links are distinct in the long and short term.

Why South Korea? South Korea is the 8th biggest emitter in the world with GDP and GDP per capita amounting to USD 1.647 trillion and USD 31,846.22, respectively, in 
2019 [19]. South Korea is the 3rd biggest LNG importer in the world in 2019. South Korea has established a goal of being carbon neutral by 2050 by expanding the percentage of renewable sources of energy, progressively phasing out coal, improving energy efficiency, and nurturing the nation's nascent hydrogen sector. In 2034, renewables should account for $40 \%$ of total capacity, whereas coal and nuclear should account for $10 \%$ and $15 \%$ of total capacity, respectively. To meet this goal, South Korea will need to considerably enhance its climate policies, especially if it wants to reach carbon neutrality by 2050, including modifying and improving its 2030 NDC to comply with the Paris Accord. South Korea total energy mix consists of renewable sources (3\%), petroleum and other liquids (43\%) natural gas (16\%), coal (28\%), and nuclear (10\%) [20]

Thus, the present research tends to assess the influence of globalization and technological innovation on $\mathrm{CO}_{2}$ emissions as well as take into account the role of renewable energy and energy consumption in South Korea between 1980 and 2018. The study contributes to the ongoing literature in the following ways; first, this is the first study investigating this association for the case of South Korea. Second, we applied ARDL approach to capture the short- and long-run interconnection between $\mathrm{CO}_{2}$ emissions and the regressors. Third, we applied the frequency domain causality test to catch the causal association between $\mathrm{CO}_{2}$ and REC, GDP, GLO, TI and EC. The major advantage of this technique is that it can catch causal linkage between series at different frequencies. Table 1 presents the synopsis of the related studies.

The next segment presents empirical methodology. Section 3 presents findings and discussion. Section 4 concludes the empirical analysis.

Table 1. Summary of studies.

\begin{tabular}{|c|c|c|c|c|}
\hline Authors & Period & Country(s) & Technique(s) Used & Findings \\
\hline \multicolumn{5}{|c|}{ Impact of Energy Use and Economic Growth on $\mathrm{CO}_{2}$ Emissions } \\
\hline Adebayo [21] & 1970-2016 & Mexico & ARDL, Granger Causality & $\begin{array}{c}\mathrm{GDP} \rightarrow \mathrm{CO}_{2}(+) \\
\mathrm{GDP} \rightarrow \mathrm{CO}_{2} \\
\mathrm{EC} \rightarrow \mathrm{CO}_{2}(+) \\
\mathrm{EC} \rightarrow \mathrm{CO}_{2}\end{array}$ \\
\hline Awosusi et al. [3] & 1965-2019 & South Korea & $\begin{array}{l}\text { ARDL, Wavelet Tools, } \\
\text { Granger Causality }\end{array}$ & $\begin{array}{c}\mathrm{GDP} \rightarrow \mathrm{CO}_{2}(+) \\
\mathrm{GDP} \rightarrow \mathrm{CO}_{2} \\
\mathrm{GDP} \rightarrow \mathrm{CO}_{2}(+)\end{array}$ \\
\hline Olanrewaju et al. [22] & 1970-2016 & Thailand & ARDL, Granger Causality & $\begin{array}{c}\mathrm{GDP} \rightarrow \mathrm{CO}_{2} \\
\mathrm{EC} \rightarrow \mathrm{CO}_{2}(+) \\
\mathrm{EC} \rightarrow \mathrm{CO}_{2}\end{array}$ \\
\hline Bekun et al. [23] & 1965-2019 & Indonesia & ARDL, Wavelet Tools & $\begin{array}{c}\mathrm{GDP} \rightarrow \mathrm{CO}_{2}(+) \\
\mathrm{GDP} \rightarrow \mathrm{CO}_{2} \\
\mathrm{GDP} \rightarrow \mathrm{CO}_{2}(+)\end{array}$ \\
\hline He et al. [24] & 1990-2018 & Mexico & $\begin{array}{l}\text { ARDL, Frequency Domain } \\
\text { Causality }\end{array}$ & $\begin{array}{c}\mathrm{GDP} \rightarrow \mathrm{CO}_{2} \\
\mathrm{EC} \rightarrow \mathrm{CO}_{2}(+) \\
\mathrm{EC} \rightarrow \mathrm{CO}_{2}\end{array}$ \\
\hline Orhan et al. [25] & 1970-2019 & India & Wavelet Coherence & $\mathrm{GDP} \rightarrow \mathrm{CO}_{2}$ \\
\hline Soylu et al. [26] & 1965-2019 & China & PWC, MWC, WC & $\begin{aligned} & \mathrm{GDP} \rightarrow \mathrm{CO}_{2}(+) \\
& \mathrm{EC} \rightarrow \mathrm{CO}_{2}(+)\end{aligned}$ \\
\hline \multicolumn{5}{|c|}{ Impact of Globalization on $\mathrm{CO}_{2}$ Emissions } \\
\hline Zaidi et al. [18] & 1960-2016 & APEC Nations & CUP, Panel Causality & $\begin{array}{c}\mathrm{GLO} \rightarrow \mathrm{CO}_{2}(-) \\
\mathrm{GLO} \rightarrow \mathrm{CO}_{2}\end{array}$ \\
\hline Oluwajana et al. [27] & 1980-2018 & South Africa & $\begin{array}{l}\text { ARDL, Frequency Domain } \\
\text { Causality }\end{array}$ & $\begin{array}{c}\mathrm{GLO} \rightarrow \mathrm{CO}_{2}(+) \\
\mathrm{GLO} \rightarrow \mathrm{CO}_{2}\end{array}$ \\
\hline Haseeb et al. [17] & 1994-2014 & BRICS nations & Panel DOLS, FMOLS & $\begin{array}{c}\mathrm{GLO} \rightarrow \mathrm{CO}_{2}(-) \\
\mathrm{GLO} \leftrightarrow \mathrm{CO}_{2} \\
\text { For Advanced nations }\end{array}$ \\
\hline Muhammad and Khan [28] & 1991-2018 & $\begin{array}{l}155 \text { emerging and } \\
\text { advanced Nations }\end{array}$ & GMM & $\begin{array}{c}\mathrm{GLO} \rightarrow \mathrm{CO}_{2}(-) \\
\text { For Developing Nations } \\
\text { GLO } \rightarrow \mathrm{CO}_{2}(+)\end{array}$ \\
\hline Pata [29] & 1971-2016 & Brazil and China & $\begin{array}{c}\text { Fourier ADL } \\
\text { cointegration, Granger } \\
\text { Causality }\end{array}$ & $\mathrm{GLO} \rightarrow \mathrm{CO}_{2}$ \\
\hline
\end{tabular}


Table 1. Cont.

\begin{tabular}{|c|c|c|c|c|}
\hline Authors & Period & Country(s) & Technique(s) Used & Findings \\
\hline \multicolumn{5}{|c|}{ Impact of Renewable Energy Consumption on $\mathrm{CO}_{2}$ Emissions } \\
\hline Kirikkaleli and Adebayo [30] & 1970-2018 & Global Economy & $\begin{array}{l}\text { FMOLS, DOLS, BC } \\
\text { Causality }\end{array}$ & $\begin{array}{c}\mathrm{REC} \rightarrow \mathrm{CO}_{2}(-) \\
\mathrm{REC} \rightarrow \mathrm{CO}_{2}\end{array}$ \\
\hline Altinoz and Dogan [31] & 1990-2014 & 82 countries & ARDL & $\begin{array}{c}\mathrm{REC} \rightarrow \mathrm{CO}_{2}(-) \\
\mathrm{REC} \rightarrow \mathrm{CO}_{2}\end{array}$ \\
\hline Pata [32] & 1991-2018 & $\begin{array}{l}\text { BRICS and developing } \\
\text { countries }\end{array}$ & GMM & $\mathrm{REC} \rightarrow \mathrm{CO}_{2}(-)$ \\
\hline Mohsin et al. [33] & 2000-2016 & $\begin{array}{c}25 \text { developing Asian } \\
\text { countries }\end{array}$ & Panel FMOLS & $\mathrm{REC} \rightarrow \mathrm{CO}_{2}(-)$ \\
\hline \multicolumn{5}{|c|}{ Impact of Technological Innovation on $\mathrm{CO}_{2}$ Emissions } \\
\hline Adebayo and Kirikkaleli [2] & 1990Q1-2015Q4 & Japan & Wavelet Tools & $\begin{array}{l}\mathrm{TI} \rightarrow \mathrm{CO}_{2}(-) \\
\mathrm{TI} \rightarrow \mathrm{CO}_{2}\end{array}$ \\
\hline Cheng et al. [34] & 2005Q1-2018Q4 & China & ARDL & $\mathrm{TI} \rightarrow \mathrm{CO}_{2}(-)$ \\
\hline Ahmad et al. [35] & 1990-2014 & OECD economies & Panel FMOLS & $\mathrm{TI} \rightarrow \mathrm{CO}_{2}(-)$ \\
\hline Dauda et al. [9] & 1990 to 2016 & & Panel Techniques & $\mathrm{TI} \neq \mathrm{CO}_{2}$ \\
\hline
\end{tabular}

\section{Materials and Methods}

In the empirical analysis, it is vital to ascertain the series order of integration by applying stationarity tests. Thus, the present research utilized ADF and PP unit root test to catch the order of integration of the series. Furthermore, it is known that if series exhibit break(s), utilizing the ADF and PP tests will yield incorrect outcomes. Therefore, the current research utilized Zivot and Andrews' unit root test to catch a series unit root and a single break. Following the studies of He et al. [4] for Mexico, Oluwajana et al. [27] for South Africa, and Chien et al. [36] for Pakistan, the current research assesses the influence of technological innovation and renewable energy use on $\mathrm{CO}_{2}$ emissions. This study takes a step further by incorporating globalization into their model. In line with these prior studies, the present research formulated the model as follows:

$$
\mathrm{CO}_{2 t}=\beta_{1}+\beta_{2} \mathrm{GDP}+\beta_{3} \mathrm{EC}+\beta_{4} R E C+\beta_{5} \mathrm{GLO}+\beta_{6} \mathrm{TI}+\varepsilon_{t}
$$

In Equation (1), $\mathrm{CO}_{2}$ stands for emissions per capita, GDP denotes economic growth which is measured as GDP per capita (USD Constant 2020), EC stands for energy use which is measured as primary energy use per capita (KWh), REC means renewable energy use which is measured as renewable energy use per Capita (KWh), GLO stands for globalization which is measured as social, economic and political globalization, and TI represents technological innovation which is measured as the addition of both nonresident and resident patent application. The data utilized in this study stretched from the period 1980 to 2018 (39 observations). The $\mathrm{CO}_{2}, \mathrm{REC}$, and EC data are obtained from the British petroleum database while technological innovation and GDP data are gathered from the database of the World Bank.

In line with the studies of Awosusi et al. [3], Alola et al. [37] and Sarkodie et al. [38], we added GDP into the model. Furthermore, following the studies of Adebayo et al. [21], Rjoub et al. [39] and He et al. [24], we incorporate energy use into the model. REC was incorporated into the model in line with the studies of Kirikkaleli and Adebayo [40], Ahmed et al. [7] and Adebayo and Kirikkaleli [40]. Additionally, we incorporate GLO into the model following the studies of Kirkkaleli et al. [41], Adebayo and Kirikkaleli [2] and Oluwajana et al. [27]. Lastly, we introduced TI into the model following the studies of Kirikkaleli and Adebayo [30], Khan et al. [42] and Shahbaz et al. [10].

The study applied the ARDL bounds test to capture the long-run association between $\mathrm{CO}_{2}$ emissions, technological innovation, economic growth, renewable energy consumption and energy consumption. The null and alternative hypotheses are no cointegration and there is cointegration among the variables [43]. Bounds tests based on the ARDL approach is represented by the following model: 


$$
\begin{gathered}
\Delta C O_{2 t}=\beta_{1}+\sum_{i=1}^{k} \beta_{2} \Delta C O_{2 t-\mathrm{i}}+\sum_{i=1}^{k} \beta_{3} \Delta G D P_{t-\mathrm{i}}+\sum_{i=1}^{k} \beta_{4} \Delta \mathrm{EC}_{t-\mathrm{i}}+\sum_{i=1}^{k} \beta_{5} \Delta R E C_{t-\mathrm{i}}+\sum_{i=1}^{k} \beta_{6} \Delta G L O_{t-\mathrm{i}}+\sum_{i=1}^{k} \beta_{7} \Delta T I_{t-\mathrm{i}} \\
+\beta_{8} C O_{2 t-\mathrm{i}}+\beta_{9} G D P_{t-\mathrm{i}}+\beta_{10} E C_{t-\mathrm{i}}+\beta_{11} R E C_{t-\mathrm{i}}+\beta_{12} G L O_{t-\mathrm{i}}+\beta_{13} T I_{t-i}+\varepsilon_{t}
\end{gathered}
$$

In Equation (2), the difference operator is depicted by $\Delta$ and $\beta^{\prime}$ s represents the coefficients. In order to collect information regarding our model's short-run divergence from its long-run equilibrium, we used an error correction model (ECM), which states that short-term imbalances are corrected by an error. Equation (3) represents the ECM model as follows:

$$
\begin{gathered}
\Delta C O_{2 t}=\beta_{1}+\sum_{i=1}^{k} \beta_{2} \Delta C O_{2 t-i}+\sum_{i=1}^{k} \beta_{3} \Delta G D P_{t-i}+\sum_{i=1}^{k} \beta_{4} \Delta E C_{t-i}+\sum_{i=1}^{k} \beta_{5} \Delta R E C_{t-i}+\sum_{i=1}^{k} \beta_{6} \Delta G L O_{t-i}+\sum_{i=1}^{k} \beta_{7} \Delta T I_{t-i} \\
+\beta_{8} E C T_{t-1}+\varepsilon_{t}
\end{gathered}
$$

The speed of adjustment coefficient is depicted by $\beta_{8}$. ECT stands for error correction term. $\Delta$ stands for the changes of the variables which they are attached. Time is illustrated by $\mathrm{t}$ and $\varepsilon$ represents error term. The ECT coefficient must be negative and significant.

Lastly, following the study of Breitung and Candelon [44], the present research applied the frequency domain causality test. In contrast to the time-domain technique, which displays the variability of the time series, the test indicates the degree of this precise fluctuation. This methodology is referred to as the spectral causality technique. In research with short series, a seasonal model can be vital, and the frequency domain can help to remove this variance. Furthermore, using a frequency-domain technique allows us to track nonlinearity and causal cycles at high and low frequencies. The major advantage of this approach is that causal linkage between series can be captured at short, medium and long term, respectively.

\section{Findings and Discussion}

Having a brief understanding of variables under investigation is essential in empirical analysis. Therefore, the current research utilized the RADAR chart to illustrate the variables' descriptive statistics. Figure 1 depicts the RADAR descriptive statistics of the variables. Technological innovation has the highest mean value which is followed by economic growth, energy use, globalization, $\mathrm{CO}_{2}$, and renewable energy use. Regarding standard deviation, the globalization score is better which is followed by $\mathrm{CO}_{2}, \mathrm{REC}, \mathrm{GDP}, \mathrm{EC}$ and TI. All the series of investigations are negatively skewed with the exemption of REC which is positively skewed. Furthermore, all the series of study are platykurtic in nature since their values are less than 3 with the exemption of REC which is leptokurtic in nature.

Furthermore, it is crucial to catch the series other of integration before commencing on additional analysis. Based on this, the present study utilized both traditional unit root tests and Zivot and Andrews' (ZA) stationarity tests. The outcomes of the ADF and PP stationarity tests are presented in Table 2. The outcome disclosed that at level, all the series are non-stationary. Nonetheless, after the first difference is taken, all the series are found stationary which suggest that all series are I(1) variables. It is generally established that the conventional stationarity tests will yield inaccurate outcome if there is a break in series. Thus, the ZA unit test is utilized to solve this issue. The outcomes of the ZA are depicted in Table 3 and their outcomes disclosed that all the series are non-stationary at level. Nonetheless, after the series' first difference is taken, all the series are stationary at first difference. We progressed to the cointegration test after confirming that the series are of order (1). The Bounds test outcome is disclosed in Table 4. The F-statistic (6.76) is greater than the lower and upper critical value at $1 \%, 5 \%$ and $10 \%$ significance level. This implies that the null hypothesis of no cointegration is rejected suggesting proof of longrun association between $\mathrm{CO}_{2}$ emissions and economic growth, technological innovation, renewable energy consumption and energy consumption. 


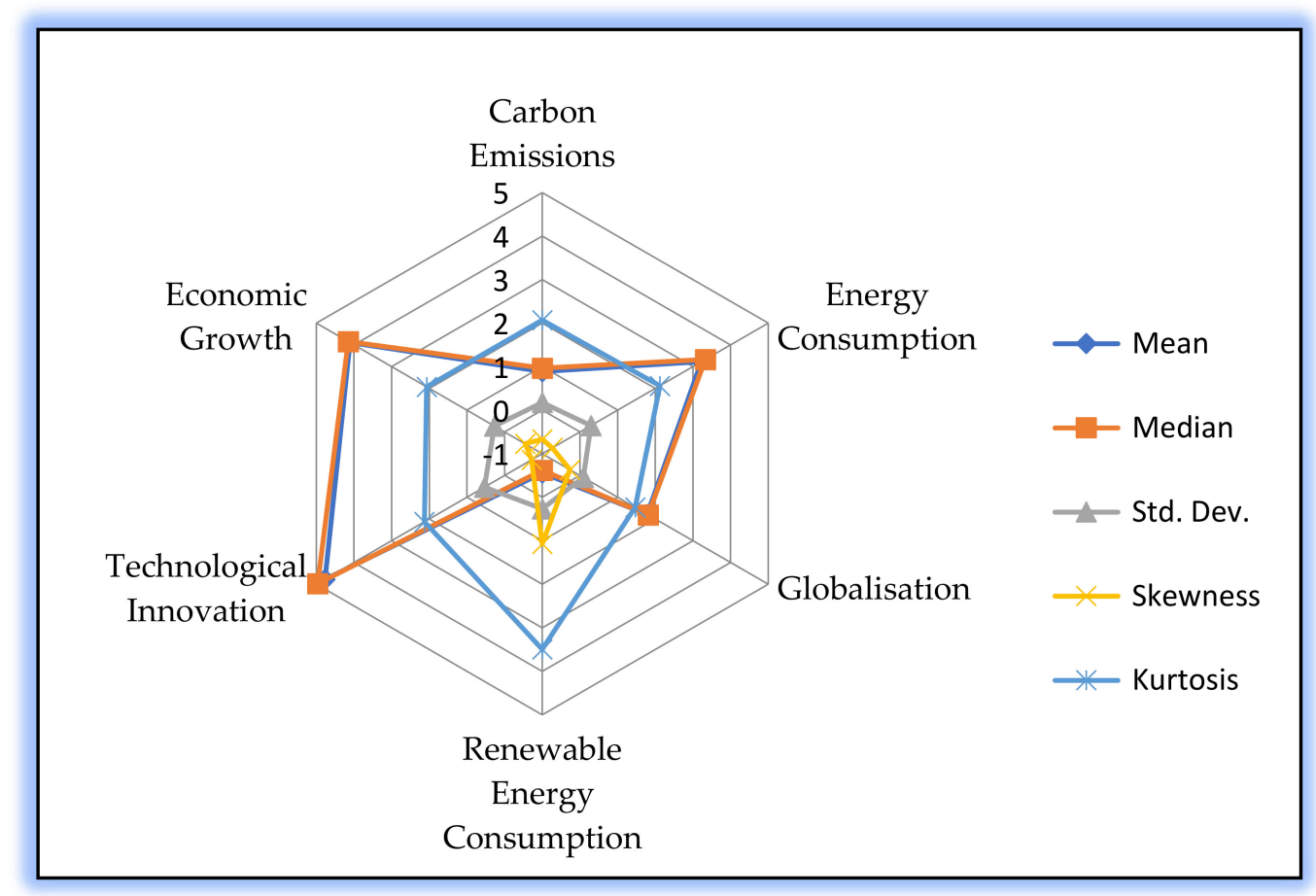

Figure 1. Descriptive statistics.

Table 2. ADF and PP tests.

\begin{tabular}{ccccc}
\hline & \multicolumn{2}{c}{ ADF } & \multicolumn{2}{c}{ PP } \\
\hline Variables & Level & First Difference & Level & First Difference \\
CO2 & -1.0957 & $-6.2803^{*}$ & -0.9183 & $-6.7159^{*}$ \\
GDP & -0.6664 & $-6.4591^{*}$ & -0.3546 & $-10.160^{*}$ \\
REC & -2.0133 & $-6.0307^{*}$ & -2.0133 & $-20.106^{*}$ \\
GLO & -1.0407 & $-4.3327^{*}$ & -1.4199 & $-4.2704^{*}$ \\
EC & 0.0489 & $-5.0848^{*}$ & -0.1406 & $-5.0391^{*}$ \\
TI & -1.1665 & $-5.4308^{*}$ & 0.2867 & $-8.0468^{*}$ \\
\hline
\end{tabular}

Note: * represent $1 \%$, level of significance.

Table 3. ZA tests.

\begin{tabular}{ccccc}
\hline & \multicolumn{2}{c}{ Level } & \multicolumn{2}{c}{ First Difference } \\
\hline Variables & T-Statistics & BD & T-Statistics & BD \\
$\mathrm{CO}_{2}$ & $-5.1778^{* *}$ & 1998 & $-7.388^{*}$ & 1998 \\
$\mathrm{GDP}$ & -4.879 & 2006 & $-7.046^{*}$ & 1998 \\
$\mathrm{REC}$ & -5.6645 & 2006 & $-6.054^{*}$ & 1994 \\
$\mathrm{GLO}$ & -3.0211 & 1993 & $-6.125^{*}$ & 1988 \\
$\mathrm{EC}$ & -4.9090 & 1996 & $-7.165^{*}$ & 1998 \\
TI & -4.3905 & 1995 & $-5.901^{*}$ & 1997 \\
\hline
\end{tabular}

Note: ${ }^{*}$, and ${ }^{* *}$ represent $1 \%$, and $5 \%$ level of significance.

Table 4. Bound test.

\begin{tabular}{|c|c|c|c|c|c|c|}
\hline \multirow[b]{4}{*}{ F-statistics CV } & \multicolumn{2}{|c|}{ F-Statistics } & \multicolumn{2}{|c|}{15.42411 * } & & \\
\hline & \multicolumn{2}{|c|}{ Cointegration } & \multicolumn{2}{|c|}{ Yes } & \multirow{2}{*}{\multicolumn{2}{|c|}{$1 \%$}} \\
\hline & \multicolumn{2}{|c|}{$10 \%$} & \multicolumn{2}{|c|}{$5 \%$} & & \\
\hline & 2.26 & 3.35 & 2.62 & 3.79 & 3.41 & 4.68 \\
\hline
\end{tabular}

Note: ${ }^{*}$ represent a $1 \%$ level of significance.

After the cointegration among the series of interest is established, we move forward by examining the influence of GDP, REC, EC and GLO on $\mathrm{CO}_{2}$ emissions in South Korea. This 
is done by applying the ARDL approach to capture concurrently both short- and long-run association between $\mathrm{CO}_{2}$ emissions and the regressors. The outcomes of the ARDL short and Long-run estimate is depicted in Table 5. The outcomes of the ARDL estimation disclosed the following: GDP and $\mathrm{CO}_{2}$ are positively connected which infers that when holding other indicators constant, $1 \%$ upsurge in GDP will trigger $\mathrm{CO}_{2}$ emissions in South Korea by $0.38 \%$. This is unsurprising considering that the economy of South Korea is predominantly an investment-oriented and manufacturing economy that strongly depends on the use of energy; nevertheless, altering the energy mix to include more renewable choices including wind and solar energy has the capability to minimize $\mathrm{CO}_{2}$ emissions. This outcome complies with the studies of Kirikkaleli and Adebayo [40] for India, Soylu et al. [26] for India, Orhan et al. [25] for China, Tufail et al. [45] for highly decentralized economies and Bekun et al. [23] for Indonesia who established that GDP triggers $\mathrm{CO}_{2}$ emissions positively.

Table 5. ARDL long- and short -outcomes.

\begin{tabular}{|c|c|c|c|c|c|c|c|c|}
\hline \multirow[b]{2}{*}{ Variable } & \multicolumn{4}{|c|}{ Long-Run Outcomes } & \multicolumn{4}{|c|}{ Short-Run Outcomes } \\
\hline & Coefficient & Std. Error & t-Statistic & Prob & Coefficient & Std. Error & $\mathrm{t}$-Statistic & Prob \\
\hline EC & $1.098 *$ & 0.156 & 6.998 & 0.000 & $1.098 *$ & 0.120 & 9.132 & 0.000 \\
\hline GDP & $0.385^{* * *}$ & 0.222 & 1.732 & 0.094 & $0.385^{* *}$ & 0.148 & 2.588 & 0.015 \\
\hline GLO & $1.606 *$ & 0.206 & 7.788 & 0.000 & $1.606^{*}$ & 0.147 & 10.90 & 0.000 \\
\hline REC & -0.007 & 0.010 & -0.724 & 0.475 & -1.008 & 0.173 & -1.000 & 0.325 \\
\hline $\mathrm{TI}$ & $-0.081^{* *}$ & 0.033 & -2.414 & 0.022 & -0.036 & 0.027 & -1.323 & 0.196 \\
\hline $\mathrm{ECT}(-1)$ & & & & & $-0.110 *$ & 0.010 & -10.47 & 0.000 \\
\hline $\mathrm{R}^{2}$ & 0.98 & & & & & & & \\
\hline Adj- $R^{2}$ & 0.97 & & & & & & & \\
\hline F-stat & 1161.5 & & & & & & & \\
\hline $\begin{array}{c}\text { Prob(F- } \\
\text { stat) }\end{array}$ & 0.000 & & & & & & & \\
\hline
\end{tabular}

Note: ${ }^{* * *}$ and ${ }^{* * *}$ represent $1 \%, 5 \%$ and $10 \%$ level of significance.

Energy use impacted $\mathrm{CO}_{2}$ emissions positively in South Korea which implies that a $1.09 \%$ upsurge in $\mathrm{CO}_{2}$ emissions is due to a $1 \%$ increase in the utilization of energy when other indicators are kept constant. The key reason for the positive energy use and $\mathrm{CO}_{2}$ emissions association in South Korea is due to the country's substantial nonrenewable energy usage. Furthermore, this result is unsurprising, given that coal and petroleum, and other liquids account for $71 \%$ of total primary energy use. It requires time, technology, and a large fixed cost to shift from nonrenewable to renewable energy sources. This is why nuclear and natural gas power plants are viewed as low-carbon alternatives to coal and oil power plants. This outcome agrees with past studies [22-25] which established positive energy use and $\mathrm{CO}_{2}$ emissions association.

REC exerts a negative and insignificant impact on $\mathrm{CO}_{2}$ which implies that REC does not aid in mitigating $\mathrm{CO}_{2}$ emissions in South Korea. This is not surprising given the fact that REC accounts for a small fraction (3\%) of the South Korea energy mix.

Globalization impacts $\mathrm{CO}_{2}$ positively which infers that when keeping other indicators constant, $1 \%$ upsurge in globalization will cause $\mathrm{CO}_{2}$ emissions to rise by $1.60 \%$ keeping other indicators constant. The probable reason for this association is that globalization process enables developed nations to transmit superior technology to developing countries, which helps these countries expand the division of labor and boost their comparative advantage. Globalization also boosts total factor productivity through increasing commerce. It enhances the activity of the economy by FDI and the transfer of sophisticated technology between advanced and emerging nations. This procedure, in fact, benefits commerce, economic growth and financial markets, as well as energy consumption and the environment. As stated by Adebayo and Kirikkakeli (2021), the process of globalization triggers $\mathrm{CO}_{2}$ emissions due to the wide use of energy in the consumption and production 
of activities in both advanced and emerging economies. This outcome complies with the studies of Kirikkaleli et al. [41] for Turkey, and Oluwajana et al. [27] for South Africa.

Technological innovation exerts a negative impact on $\mathrm{CO}_{2}$ which implies that when keeping other indicators constant, a $0.08 \%$ decrease in $\mathrm{CO}_{2}$ emissions is due to a $1 \%$ increase in technological innovation. This outcome demonstrates that innovation has a significant and positive impact on environmental sustainability. The probable reason for this association is that states and industries will focus more on $\mathrm{R}$ and $\mathrm{D}$ that develops environmentally friendly capital goods and improves the efficiency of production technology that uses less energy. This outcome corroborates prior studies [30,42] that established negative technological innovation and $\mathrm{CO}_{2}$ emissions association.

The outcome of the ECT is negative and significant which demonstrates that corrections made in previous periods can be rectified in succeeding periods. Moreover, the present study conducts several diagnostic tests which are depicted in Table 6 . The outcomes disclosed that there is no heteroscedasticity and serial correlation in the model. Additionally, there is no misspecification as revealed by the RESET test. The outcomes of the CUSUM and CUSUM of Sq in Figure 2a,b uncovered that the model is stable at a 5\% level of significance.

Table 6. Diagnostic Tests.

\begin{tabular}{ccc}
\hline Tests & Value & Probability \\
\hline$\chi 2$ ARCH & 0.7060 & 0.4065 \\
$\chi 2$ RESET & 0.3518 & 0.7278 \\
$\chi 2$ Normality & 1.1290 & 0.5686 \\
$\chi 2$ LM & 1.2328 & 0.3086 \\
\hline
\end{tabular}

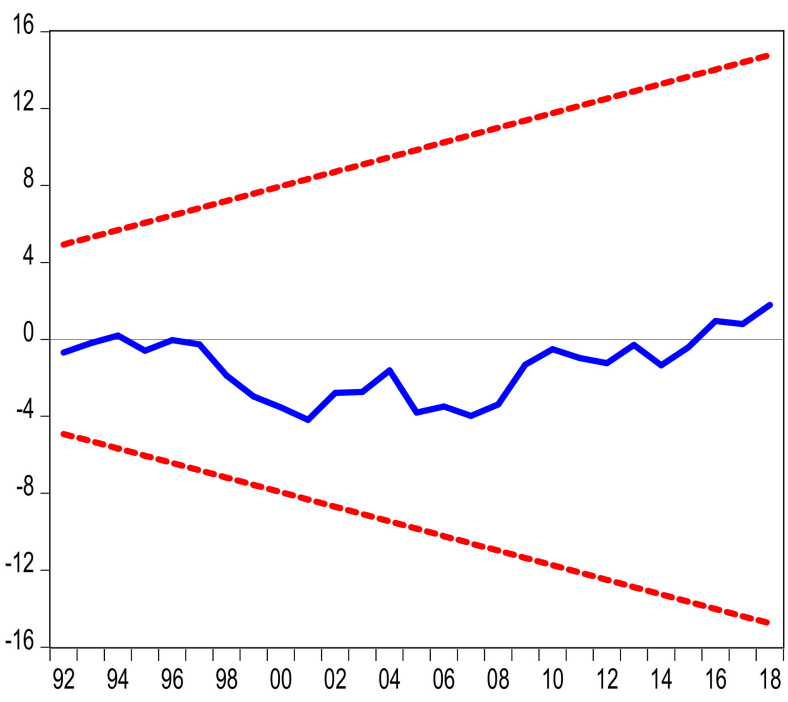

_ CUSUM $=-5 \%$ Significance

(a)

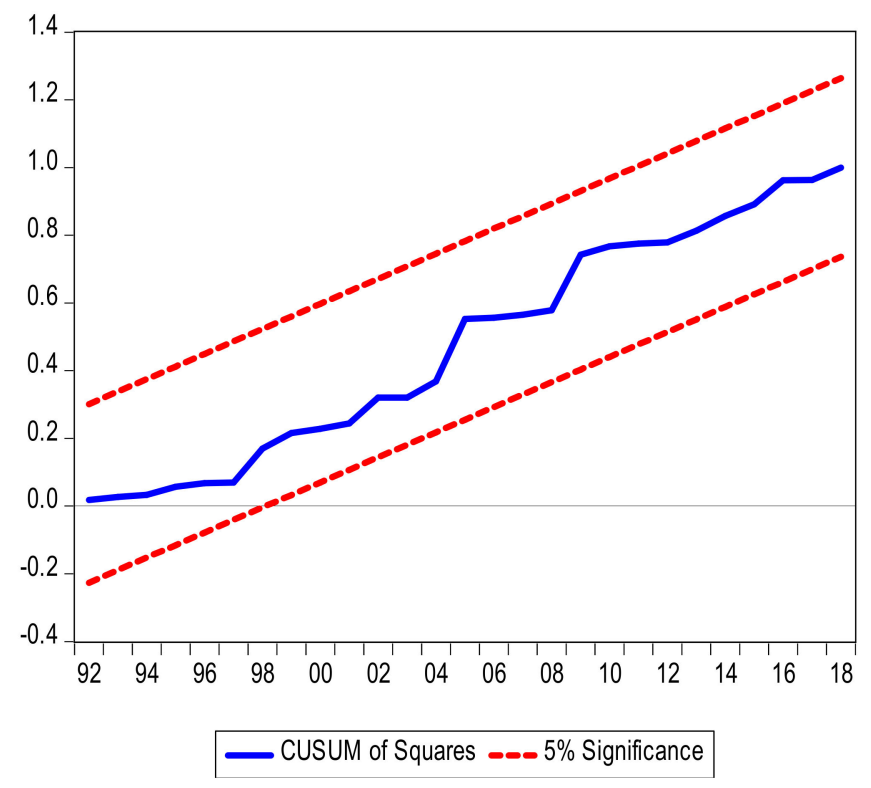

(b)

Figure 2. (a) CUSUM; (b) CUSUM of squares.

The present research takes a step further by examining the causal effects of REC, TI, GDP, EC, GLO and TI on $\mathrm{CO}_{2}$ emissions in South Korea by utilizing the $\mathrm{BC}$ causality test. The major advantage of this test is that it can capture causal linkage between series at different frequencies. Table 7 depicts the outcomes of the frequency domain causality test. At a significance level of 0.10 , the null hypothesis of no causality from $\mathrm{EC}$ to $\mathrm{CO}_{2}$ is rejected. This demonstrates that $\mathrm{EC}$ can predict $\mathrm{CO}_{2}$ emissions in the long term. This result complies with the study of Soylu et al. [26] for China, Oluwajana et al. [27] for 
South Africa, and Zhang et al. [46] for Malaysia. In the medium and short term, the null hypothesis of no causal linkage from GDP to $\mathrm{CO}_{2}$ is rejected at a $5 \%$ and $10 \%$ level of significance. This demonstrates that in the medium and short term, GDP can predict $\mathrm{CO}_{2}$. This outcome corroborates the findings of Shan et al. [47], Awosusi et al. [3] for South Korea, and Bekun et al. [23] for Indonesia. Furthermore, in the short term, the null hypothesis of no causality from GLO to $\mathrm{CO}_{2}$ is rejected at a significance level of $5 \%$ and $1 \%$, respectively. In the medium term, there is evidence of causality from TI to $\mathrm{CO}_{2}$ at a significance level of $10 \%$ in the short and medium term. This outcome demonstrates that TI can predict $\mathrm{CO}_{2}$ in both the short and medium term. This outcome complies with the studies of Kirikkaleli and Adebayo [40], Khan et al. [42] and Shahbaz et al. [10].

Table 7. Frequency domain causality test.

\begin{tabular}{ccccccc}
\hline & \multicolumn{2}{c}{ Long-Term } & \multicolumn{2}{c}{ Medium-Term } & \multicolumn{2}{c}{ Short-Term } \\
\hline Causality Path & $\mathrm{w}_{\mathrm{i}}=0.01$ & $\mathrm{w}_{\mathrm{i}}=0.05$ & $\mathrm{w}_{\mathrm{i}}=1.00$ & $\mathrm{w}_{\mathrm{i}}=1.50$ & $\mathrm{w}_{\mathrm{i}}=2.00$ & $\mathrm{w}_{\mathrm{i}}=2.50$ \\
$\mathrm{EC} \rightarrow \mathrm{CO}_{2}$ & $5.369^{* * *}$ & $5.374^{* * *}$ & 1.4954 & 0.552 & 1.144 & 2.110 \\
$\mathrm{GDP} \rightarrow \mathrm{CO}_{2}$ & 0.857 & 0.951 & $8.162^{*}$ & $5.442^{* * *}$ & $6.981^{* *}$ & $9.895^{*}$ \\
$\mathrm{GLO} \rightarrow \mathrm{CO}_{2}$ & 0.349 & 0.390 & 3.882 & 1.8755 & $4.576^{* * *}$ & $6.964^{* *}$ \\
$\mathrm{TI} \rightarrow \mathrm{CO}_{2}$ & 1.377 & 1.386 & $4.629^{* * *}$ & $4.683^{* * *}$ & $5.643^{* * *}$ & 3.385 \\
$\mathrm{REC} \rightarrow \mathrm{CO}_{2}$ & 0.757 & 0.557 & 0.386 & 0.177 & 0.133 & 0.135 \\
\hline Note: $\rightarrow$ stands for the direction of causality. ** ${ }^{* *}$ and ${ }^{* * *}$ stands for $1 \%, 5 \%$ and $10 \%$ level of significance.
\end{tabular}

\section{Conclusions}

The present research assesses the influence of energy use and renewable energy use on $\mathrm{CO}_{2}$ emissions in South Korea as well as taking into account the role of globalization and technological innovation. The study utilized yearly data stretching between 1980 and 2018 as well as recent econometric techniques to capture this interconnection. The outcomes of the ADF, PP and ZA disclosed that all the series are I(1) variables which give room for the utilization of the ARDL bounds test. The outcomes of the ARDL bounds test disclosed a long-run association between $\mathrm{CO}_{2}$ emissions and regressors. Furthermore, we applied the ARDL approach to catch the long- and short-run linkages between $\mathrm{CO}_{2}$ emissions and the regressors. The outcomes of the ARDL long- and short-run estimate disclosed that GDP, globalization, and energy use triggers $\mathrm{CO}_{2}$ emissions while technological innovation improves it. Moreover, the present research assesses the causal linkage between the series at different frequencies by applying the frequency domain causality test. The major advantage of this test is that it can capture causal linkage between series at different frequencies (small-, medium- and long-term). The outcomes of the causality test disclosed that technological innovation, globalization, economic growth and energy use can predict $\mathrm{CO}_{2}$ emissions.

Our research findings have just a few policy ramifications. The findings imply that economic expansion in South Korea has negative environmental consequences. The worldwide level, which demonstrates that South Korea's economic growth is strongly reliant on the utilization of energy, is a major impediment to reducing $\mathrm{CO}_{2}$ emissions. Environmental costs may rise as a result of increased energy usage, which leads to environmental resource catastrophes and global warming. As a result, one effective strategy to cut $\mathrm{CO}_{2}$ is to minimize the nation's reliance on nonrenewable sources of energy (e.g., natural gas, petroleum and coal) and invest more in the nation's renewable energy sources (e.g., wind, nuclear power and solar). Additionally, globalization impacts $\mathrm{CO}_{2}$ emissions positively in South Korea as disclosed by the empirical finding. Globalization has been identified as a significant contributor to the rise in $\mathrm{CO}_{2}$ emissions. Thus, the government should consider the social, economic and environmental aspects of globalization. Furthermore, according to the empirical findings, it is critical to invest in technological innovation in order to reduce $\mathrm{CO}_{2}$ emissions since technological innovation not only helps to minimize $\mathrm{CO}_{2}$ emissions but also discovers new and inventive methods to use conventional sources of energy efficiently. Technological innovation also aids in the production of new renewable energy sources at a cheaper cost. As a result, technological innovation not only effectively uses both traditional and renewable energy sources but also offers a cost-effective alternative 
in today's world, where energy consumption has become an integral component of the economic growth process. Renewable energy consumption has a negative and insignificant influence on $\mathrm{CO}_{2}$ emissions, according to the findings. As a result, South Korea must increase its investment in renewable energy. It is a well-known fact that green energy emits less carbon than conventional sources of energy such as fossil fuels. Furthermore, green sources of energy are both cost-effective and efficient. To fulfill South Korea's high energy demand, the government must take a significant step by increasing the total percentage of renewable energy in the total energy mix.

Additionally, while $\mathrm{CO}_{2}$ emissions are used as a proxy for environmental deterioration, they are not the only indicator of environmental deterioration. More research should be done in South Korea to investigate this relation by including additional environmental degradation variables.

Author Contributions: All the authors contributed equally in this manuscript. All authors have read and agreed to the published version of the manuscript.

Funding: This research was supported by Instituto Politécnico de Lisboa.

Data Availability Statement: Data is readily available at request.

Acknowledgments: We thank Instituto Politécnico de Lisboa for providing funding for this study.

Conflicts of Interest: The authors declare no conflict of interest.

\section{References}

1. BP. 2019. Available online: https://www.bp.com/en/global/corporate/energy-economics/statistical-review-of-world-energy/ co2-emissions.html (accessed on 29 May 2021).

2. Adebayo, T.S.; Kirikkaleli, D. Impact of renewable energy consumption, globalization, and technological innovation on environmental degradation in Japan: Application of wavelet tools. Environ. Dev. Sustain. 2021, 1-26. [CrossRef]

3. Adebayo, T.S.; Awosusi, A.A.; Kirikkaleli, D.; Akinsola, G.D.; Mwamba, M.N. Can $\mathrm{CO}_{2}$ emissions and energy consumption determine the economic performance of South Korea? A time series analysis. Environ. Sci. Pollut. Res. 2021, 1-16. [CrossRef]

4. Adebayo, T.S.; Adedoyin, F.F.; Kirikkaleli, D. Toward a sustainable environment: Nexus between consumption-based carbon emissions, economic growth, renewable energy and technological innovation in Brazil. Environ. Sci. Pollut. Res. 2021, 1-11. [CrossRef]

5. Ahmed, Z.; Wang, Z.; Mahmood, F.; Hafeez, M.; Ali, N. Does globalization increase the ecological footprint? Empirical evidence from Malaysia. Environ. Sci. Pollut. Res. 2019, 26, 18565-18582. [CrossRef] [PubMed]

6. Jin, L.; Duan, K.; Shi, C.; Ju, X. The Impact of Technological Progress in the Energy Sector on Carbon Emissions: An Empirical Analysis from China. Int. J. Environ. Res. Public Health 2017, 14, 1505. [CrossRef]

7. Ahmad, M.; Khan, Z.; Rahman, Z.U.; Khattak, S.I.; Khan, Z.U. Can innovation shocks determine $\mathrm{CO}_{2}$ emissions $\left(\mathrm{CO}_{2} \mathrm{e}\right)$ in the OECD economies? A new perspective. Econ. Innov. New Technol. 2021, 30, 89-109. [CrossRef]

8. Su, H.-N.; Moaniba, I.M. Does innovation respond to climate change? Empirical evidence from patents and greenhouse gas emissions. Technol. Forecast. Soc. Chang. 2017, 122, 49-62. [CrossRef]

9. Dauda, L.; Long, X.; Mensah, C.N.; Salman, M.; Boamah, K.B.; Ampon-Wireko, S.; Dogbe, C.S.K. Innovation, trade openness and $\mathrm{CO}_{2}$ emissions in selected countries in Africa. J. Clean. Prod. 2021, 281, 125143. [CrossRef]

10. Shahbaz, M.; Raghutla, C.; Song, M.; Zameer, H.; Jiao, Z. Public-private partnerships investment in energy as new determinant of $\mathrm{CO}_{2}$ emissions: The role of technological innovations in China. Energy Econ. 2020, 86, 104664. [CrossRef]

11. Ali, W.; Abdullah, A.; Azam, M. The dynamic linkage between technological innovation and carbon dioxide emissions in Malaysia: An autoregressive distributed lagged bound approach. Int. J. Energy Econ. Policy 2016, 6, 389-400.

12. Shaari, M.S.; Abdullah DN, C.; Alias, N.S.; Adnan NS, M. Positive and negative effects of research and development. Int. J. Energy Econ. Policy 2016, 6, 767-770.

13. Garrone, P.; Grilli, L. Is there a relationship between public expenditures in energy R\&D and carbon emissions per GDP? An empirical investigation. Energy Policy 2010, 38, 5600-5613. [CrossRef]

14. Kalayci, C. The impact of economic globalization on $\mathrm{CO}_{2}$ emissions: The case of NAFTA countries. Int. J. Energy Econ. Policy 2019, 9, 356.

15. Rahman, M.M. Environmental degradation: The role of electricity consumption, economic growth and globalisation. J. Environ. Manag. 2020, 253, 109742. [CrossRef]

16. Shahbaz, M.; Shahzad, S.J.H.; Mahalik, M.K.; Sadorsky, P. How strong is the causal relationship between globalization and energy consumption in developed economies? A country-specific time-series and panel analysis. Appl. Econ. 2018, 50, 1479-1494. [CrossRef] 
17. Haseeb, A.; Xia, E.; Danish; Baloch, M.A.; Abbas, K. Financial development, globalization, and $\mathrm{CO}_{2}$ emission in the presence of EKC: Evidence from BRICS countries. Environ. Sci. Pollut. Res. 2018, 25, 31283-31296. [CrossRef] [PubMed]

18. Zaidi, S.A.H.; Zafar, M.W.; Shahbaz, M.; Hou, F. Dynamic linkages between globalization, financial development and carbon emissions: Evidence from Asia Pacific Economic Cooperation countries. J. Clean. Prod. 2019, 228, 533-543. [CrossRef]

19. World Bank. World Development Indicators. Washington. 2020. Available online: http://data.worldbank.org/data-catalog/ worlddevelopment- (accessed on 15 May 2021).

20. BP. 2021. Available online: https://www.bp.com/content/dam/bp/business-sites/en/global/corporate/pdfs/energy-economics/ statistical-review /bp-stats-review-2020-full-report.pdf (accessed on 15 May 2021).

21. Adebayo, T.S. Revisiting the EKC hypothesis in an emerging market: An application of ARDL-based bounds and wavelet coherence approaches. SN Appl. Sci. 2020, 2, 1-15. [CrossRef]

22. Olanrewaju, V.O.; Adebayo, T.S.; Akinsola, G.D.; Odugbesan, J.A. Determinants of Environmental Degradation in Thailand: Empirical Evidence from ARDL and Wavelet Coherence Approaches. Pollution 2021, 7, 181-196.

23. Adebayo, T.S.; Akinsola, G.D.; Kirikkaleli, D.; Bekun, F.V.; Umarbeyli, S.; Osemeahon, O.S. Economic performance of Indonesia amidst $\mathrm{CO}_{2}$ emissions and agriculture: A time series analysis. Environ. Sci. Pollut. Res. 2021, 1-15. [CrossRef]

24. He, X.; Adebayo, T.S.; Kirikkaleli, D.; Umar, M. Consumption-based carbon emissions in Mexico: An analysis using the dual adjustment approach. Sustain. Prod. Consum. 2021, 27, 947-957. [CrossRef]

25. Orhan, A.; Adebayo, T.; Genç, S.; Kirikkaleli, D. Investigating the Linkage between Economic Growth and Environmental Sustainability in India: Do Agriculture and Trade Openness Matter? Sustainability 2021, 13, 4753. [CrossRef]

26. Soylu, Ö.; Adebayo, T.; Kirikkaleli, D. The Imperativeness of Environmental Quality in China Amidst Renewable Energy Consumption and Trade Openness. Sustainability 2021, 13, 5054. [CrossRef]

27. Oluwajana, D.; Adebayo, T.S.; Kirikkaleli, D.; Adeshola, I.; Akinsola, G.D.; Osemeahon, O.S. Coal Consumption and Environmental Sustainability in South Africa: The role of Financial Development and Globalization. Int. J. Renew. Energy Dev. 2021, 10. [CrossRef]

28. Muhammad, B.; Khan, S. Understanding the relationship between natural resources, renewable energy consumption, economic factors, globalization and $\mathrm{CO}_{2}$ emissions in developed and developing countries. In Natural Resources Forum; Blackwell Publishing Ltd.: Oxford, UK, 2021; Volume 45, pp. 138-156.

29. Pata, U.K. Linking renewable energy, globalization, agriculture, $\mathrm{CO}_{2}$ emissions and ecological footprint in BRIC countries: A sustainability perspective. Renew. Energy 2021, 173, 197-208. [CrossRef]

30. Kirikkaleli, D.; Adebayo, T.S. Do renewable energy consumption and financial development matter for environmental sustainability? New global evidence. Sustain. Dev. 2020. [CrossRef]

31. Altinoz, B.; Dogan, E. How renewable energy consumption and natural resource abundance impact environmental degradation? New findings and policy implications from quantile approach. Energy Sources Part B Econ. Plan. Policy 2021, 16, 345-356. [CrossRef]

32. Pata, U.K. Renewable and non-renewable energy consumption, economic complexity, $\mathrm{CO}_{2}$ emissions, and ecological footprint in the USA: Testing the EKC hypothesis with a structural break. Environ. Sci. Pollut. Res. 2021, 28, 846-861. [CrossRef] [PubMed]

33. Mohsin, M.; Kamran, H.W.; Nawaz, M.A.; Hussain, M.S.; Dahri, A.S. Assessing the impact of transition from nonrenewable to renewable energy consumption on economic growth-environmental nexus from developing Asian economies. J. Environ. Manag. 2021, 284, 111999. [CrossRef]

34. Cheng, Y.; Awan, U.; Ahmad, S.; Tan, Z. How do technological innovation and fiscal decentralization affect the environment? A story of the fourth industrial revolution and sustainable growth. Technol. Forecast. Soc. Chang. 2021, 162, 120398. [CrossRef]

35. Adebayo, T.S.; Udemba, E.N.; Ahmed, Z.; Kirikkaleli, D. Determinants of consumption-based carbon emissions in Chile: An application of non-linear ARDL. Environ. Sci. Pollut. Res. 2021, 2021, 1-15.

36. Chien, F.; Ajaz, T.; Andlib, Z.; Chau, K.Y.; Ahmad, P.; Sharif, A. The role of technology innovation, renewable energy and globalization in reducing environmental degradation in Pakistan: A step towards sustainable environment. Renew. Energy 2021, 177, 308-317. [CrossRef]

37. Alola, A.A.; Bekun, F.V.; Sarkodie, S.A. Dynamic impact of trade policy, economic growth, fertility rate, renewable and nonrenewable energy consumption on ecological footprint in Europe. Sci. Total Environ. 2019, 685, 702-709. [CrossRef]

38. Sarkodie, S.A.; Adams, S.; Owusu, P.A.; Leirvik, T.; Ozturk, I. Mitigating degradation and emissions in China: The role of environmental sustainability, human capital and renewable energy. Sci. Total Environ. 2020, 719, 137530. [CrossRef]

39. Rjoub, H.; Odugbesan, J.A.; Adebayo, T.S.; Wong, W.-K. Sustainability of the Moderating Role of Financial Development in the Determinants of Environmental Degradation: Evidence from Turkey. Sustainability 2021, 13, 1844. [CrossRef]

40. Kirikkaleli, D.; Adebayo, T.S. Do public-private partnerships in energy and renewable energy consumption matter for consumption-based carbon dioxide emissions in India? Environ. Sci. Pollut. Res. 2021, 28, 30139-30152. [CrossRef] [PubMed]

41. Kirikkaleli, D.; Adebayo, T.S.; Khan, Z.; Ali, S. Does globalization matter for ecological footprint in Turkey? Evidence from dual adjustment approach. Environ. Sci. Pollut. Res. 2021, 28, 14009-14017. [CrossRef]

42. Khan, A.; Chenggang, Y.; Hussain, J.; Kui, Z. Impact of technological innovation, financial development and foreign direct investment on renewable energy, non-renewable energy and the environment in belt \& Road Initiative countries. Renew. Energy 2021, 171, 479-491. [CrossRef] 
43. Pesaran, M.H.; Shin, Y.; Smithc, R.J. Bounds testing approaches to the analysis of level relationships. J. Appl. Econ. 2001, 16, 289-326. [CrossRef]

44. Breitung, J.; Candelon, B. Testing for short- and long-run causality: A frequency-domain approach. J. Econ. 2006, 132, 363-378. [CrossRef]

45. Tufail, M.; Song, L.; Adebayo, T.S.; Kirikkaleli, D.; Khan, S. Do fiscal decentralization and natural resources rent curb carbon emissions? Evidence from developed countries. Environ. Sci. Pollut. Res. 2021, 1-12. [CrossRef]

46. Zhang, L.; Li, Z.; Kirikkaleli, D.; Adebayo, T.S.; Adeshola, I.; Akinsola, G.D. Modeling $\mathrm{CO}_{2}$ emissions in Malaysia: An application of Maki cointegration and wavelet coherence tests. Environ. Sci. Pollut. Res. 2021, 28, 26030-26044. [CrossRef] [PubMed]

47. Shan, S.; Ahmad, M.; Tan, Z.; Adebayo, T.S.; Li, R.Y.M.; Kirikkaleli, D. The role of energy prices and non-linear fiscal decentralization in limiting carbon emissions: Tracking environmental sustainability. Energy 2021, 234, 121243. [CrossRef] 